\title{
Um Procedimento para a Decisão de Crédito pelos Bancos
}

José Roberto Securato

Rubens Famá

\section{RESU m 0}

Analisando o procedimento da concessão de crédito pelos bancos, procuramos estabelecer de forma mais clara a avaliação do risco de crédito, captando os aspectos subjetivos existentes. Para tanto, estabelecemos uma distribuição de probabilidades em que consideramos como eventos os possíveis resultados da operação de crédito em análise na data de seu vencimento. A partir dessa distribuição obtém-se os elementos de risco da operação. Em seguida, apresentamos um critério para a decisão de crédito e formação do spread bancário, levando-se em conta a incidência do risco avaliado.

Palavras-chaves: concessão de crédito bancário, risco, risco de crédito, spread bancário.

\section{A BSTRACT}

Analyzing banks credit allowance procedures, we try to establish formally the evaluation of the credit risk taking into consideration existing subjective aspects. In order to establish a distribution of probabilities where the considered events are the possible results from the analysed credit operations at its maturity. The operational risk factors are obtained from this distribution of probability. Further we present a credit concession criteria and the creation of a banking spread, considering the risk incidence.

Key words: banks credit allowance, risk, credit risk, banking spread. 


\section{INTRO DU ÇÃ O}

Uma das questões mais importantes a que está exposto o executivo financeiro é a de conceder e obter crédito. A avaliação do crédito coloca em jogo uma decisão tomada hoje, que poderá trazer sérias conseqüências futuras. Assim a avaliação da concessão do crédito deve ser feita com exame detalhado do risco que se está correndo. A própria origem da expressão crédito significa confiar. Assim, todo crédito baseia-se na confiança, ou seja, na esperança de que o devedor pague, no futuro, pelo que lhe é fornecido no presente. Dessas considerações decorre que a concessão de crédito significa confiança, troca de coisas de valor econômico, futuridade e risco. Nas transações mercantis, na venda de mercadorias a crédito a um cliente, a companhia confia que este venha a pagar sua dívida no futuro. No caso dos bancos, essas questões são sempre mais complexas, pois podem gerar problemas de liquidez que, muitas vezes, irão custar muito caro ao acionista, quer pela elevação da taxa de captação do banco, quer pela necessidade de chamada de capital ou, na pior das hipóteses, com a própria liquidação do banco. Naturalmente estamos falando de operações de crédito a pessoas jurídicas, que podem chegar, em conjunto, a volumes significativos, que nos levam às situações descritas.

Essa questão é tão importante que o Banco Central estabelece limite para as operações de crédito, tais como:

\section{Resolução no 1559 do CMN, de 22-12-88:}

"I - Fixar em 30\% do respectivo patrimônio líquido, ajustado na forma da regulamentação em vigor, o limite de diversificação de risco por cliente...

II - Determinar que os 10 (dez) maiores clientes não poderão, em conjunto, ser responsáveis por mais de 30\% do total das operações ativas da Instituição."

\section{Resolução no 1556 do CMN, de 22-12-88:}

"I - Fixar o limite de endividamento para os Bancos..., em 15 vezes o patrimônio líquido...

II - Admitir limite adicional... equivalendo a até 5 (cinco) vezes a referida base, desde que as responsabilidades adicionais sejam decorrentes de operações executadas na qualidade de agente financeiro garantidor ou repassador de recursos de instituições e órgãos oficiais e/ou de depósitos interfinanceiros..." 
Este texto pretende examinar os procedimentos dos bancos em relação às pessoas jurídicas, às quais são concedidos créditos, o processo de avaliação desse crédito e sua relação com o risco. Em seguida, apresentamos os procedimentos e um critério que, em nossa opinião, serão bastante interessantes para avaliação do risco de crédito, possibilitando ao gestor visão mais detalhada e quantitativa do risco a que o banco estará sujeito.

\section{Procedimentos para uma O peração de Crédito}

Como os bancos avaliam o crédito das empresas com quem pretendem operar? Qual o risco assumido ao fazerem uma operação de empréstimo? Será que existe perfeita noção destas condições?

Para quem vive junto ao sistema bancário, é fácil perceber que existe grande preocupação acerca do crédito. $\mathrm{O}$ executivo de um banco sempre estará preocupado com o risco de crédito, o que é atitude no mínimo preventiva. Em momentos da conjuntura econômica, quando ocorrem apertos da liquidez, essa preocupação é maior, e os bancos ficam mais restritos em suas operações de crédito, principalmente se ocorrerem algumas concordatas ou falências.

$\mathrm{Na}$ economia brasileira, com tantas mudanças, as preocupações são sempre mais contundentes, visto que podem levar o banco a sérios problemas.

O fato é que, passados os momentos críticos, os bancos e seus executivos sabem que uma das suas principais fontes de receitas são as operações de crédito, e que os riscos por elas representados são inerentes ao negócio Banco. Todos sabem desses riscos, os banqueiros e seus executivos, e o chefe do departamento de crédito, enfim todos os participantes da avaliação do crédito. No entanto, há algo que os preocupa em relação ao risco das operações de crédito. Examinemos os procedimentos para avaliação de crédito em um banco e procuremos detectar a origem das preocupações.

\section{Início da A valiação do Crédito}

Uma operação de empréstimo de uma empresa nasce do contato entre o executivo de conta do banco com o representante da empresa, em geral seu diretor ou gerente financeiro. De início, são expostas as necessidades da empresa, a utilização dos recursos e a capacidade de pagamento dela. $\mathrm{O}$ executivo da conta, convencido dos argumentos, passa a operação para a análise de crédito. 
A primeira questão que se pode colocar é com relação ao grau de convencimento do executivo da conta. Muitas vezes não existe essa preocupação, mas a de operar, a de obter resultados. A defesa mais comum dessa questão é a observação de que os bancos $\mathrm{A}, \mathrm{B}$ ou $\mathrm{C}$ estão operando com a empresa, porque não o nosso banco? Esse procedimento do executivo da conta deve, naturalmente, ser revisto, mas de certo modo o banco já possui antídoto natural, que é seu departamento de crédito. Os homens de crédito sabem deste viés e procuram, sempre, por meio de um conjunto de informações, detectar eventuais problemas da empresa.

Passada a operação para o departamento de crédito, este irá solicitar a apresentação da documentação de praxe. Os três últimos balanços, balancetes, detalhamento do endividamento, suas fontes e aplicações, os estatutos da empresa, informações sobre os administradores e controladores, enfim os documentos habituais. Muitas vezes a análise dessa documentação é complementada com visita à empresa por um dos homens de crédito do banco e, algumas vezes, até por um dos diretores. Em geral, os departamentos de crédito dos bancos são muito competentes e minuciosos em suas análises de forma que o trabalho realizado é, na maioria das vezes, de muito boa qualidade.

Colhidas as informações e sanadas as dúvidas, é elaborada a análise de crédito, que irá compor, junto com a documentação, o dossiê da empresa. O passo seguinte é o de expor a operação aos comitês que irão aprovar ou não o crédito solicitado. Conforme o banco, haverá um ou mais comitês que examinarão a questão, atuando segundo um critério passa não passa em relação à operação de empréstimo.

Vejamos a seguir, a atuação desses comitês.

\section{Comitê de Crédito do Banco}

Em geral, existem pelo menos dois comitês de créditos em um banco. O primeiro comitê decide sobre a concessão do crédito até um limite pré-fixado; o segundo, ouvido o parecer do primeiro, decide sobre crédito acima dos limites pré-fixados.

O manual de crédito de um banco estrangeiro, para operações no Brasil, caracterizava este fato ao escrever: "o conselho de crédito tem autorização de recomendar a aprovação de operações de crédito - Resolução 767 - de até US\$ 1.000.000,00 por 1 (um) ano, e operações com garantia do Banco - capital de giro, venda de CDB, compra e venda de papéis, etc. - de até US\$1.000.000,00 por até 1 (um) ano". O conselho de crédito, neste caso, era formado pelos "participantes 
deste comitê: o presidente do conselho de administração do banco, o presidente executivo, o vice-presidente executivo e os diretores das divisões multinacional, comercial, internacional e de crédito".

Como se observa o comitê é formado da cúpula diretiva do banco no Brasil e seu limite de atuação é de US\$ 1.000.000,00 por empresa. É muito interessante um dos trechos deste manual, quando comenta as responsabilidades dos diretores quanto ao crédito: "Responsabilidade da Diretoria - além das responsabilidades normais dos diretores, os membros devem assegurar que as operações feitas no Brasil obedeçam às normas do Banco e cumpram com os altos padrões de qualidade de crédito. Dentro desta responsabilidade pelo controle do risco, os diretores devem estabelecer um esquema de revisão de créditos ativos, de limites e de físcalização das responsabilidades dos próprios gerentes de conta".

Como se observa, não se espera que a responsabilidade do comitê pela aprovação de crédito dilua a responsabilidade de um diretor, o que na prática sempre acaba ocorrendo. Haverá sempre um responsável, em maior ou menor grau, pelo crédito inconvenientemente concedido.

Em um banco menor, no início de suas atividades, a estrutura do comitê era a seguinte:

- "Comitê de Agência - aprovação por maioria

- Comitê Executivo de Crédito - formado por diretores Executivos e Operacionais

alçada: - até Cr\$ 2 milhões (equivalentes a US\$ 500 mil) - operações clean

- acima deste valor até Cr\$ 5 milhões (equivalentes a US\$ 1.250 mil) operações com garantias reais

- acima destes valores: Comitê Superior de Crédito.

- Comitê Superior de Crédito - formado pelo Presidente do banco, pelo Vicepresidente do banco e Diretores Executivos".

De um banco para outro, mudarão as formas, as composições e os limites, mas em última instância será um comitê, formado por número ímpar de pessoas, que decidirão sobre a aprovação ou não de um crédito solicitado. 


\section{A Decisão de Crédito}

Consideremos um comitê de crédito formado por um conjunto de pessoas. $\mathrm{O}$ responsável pela área de crédito apresenta a operação e o dossiê sobre a empresa em estudo. O representante da área de crédito poderá fazer ou não a sua recomendação a solicitações de crédito.

O processo seguinte é o de reexame do dossiê da empresa, discutindo-se os vários aspectos dela. Discute-se detalhadamente o balanço nos seus vários ítens, o segmento onde a empresa atua e a participação dela, as fichas tradicionais tipo SERASA ou ADVANCE, ou outras assemelhadas, da empresa como dos controladores.

Após essa discussão, em geral minuciosa, competente, estritamente profissional, chegamos à questão do sim ou não, ou sim condicional, ou ainda não provisório, aberto para o preenchimento de novas informações solicitadas pelo comitê.

Examinemos particularmente o aspecto da reunião que dará a decisão final em relação ao empréstimo. Tal decisão será sempre ou um sim, e estaremos assumindo algum nível de risco, ou um não e poderemos estar perdendo uma oportunidade. Não importa se a decisão ocorre por maioria simples, maioria absoluta ou por consenso. O fato é que a decisão ocorrerá por um critério passa não passa, sim ou não, apesar de todos os cuidados que antecederam a decisão.

É este sim ou não, do momento da decisão, que nos preocupa: como transformar um conjunto de informações em sim e outro conjunto de informações em não. Quantas vezes, no momento da decisão, um boato, que não se sabe direito de onde vem, poderá transformar a decisão em não; quantas vezes um membro do comitê diz sim, porque os demais o disseram.

As questões relativas ao instante da tomada de decisão é que acabam por comprometer todo o processo da avaliação de crédito. Não existe, explicitamente, relação clara entre avaliação do crédito e risco.

Para nós o que preocupa o banqueiro é esta relação, não bem definida, entre o crédito e o risco. É um desconforto saber que: entre um sim e um não podemos estar evitando um desastre ou perder um bom negócio.

A outra questão que se coloca é com relação às taxas de juros cobradas por 
empréstimos. Aprovados os créditos para duas empresas, de qualidades distintas, as taxas são distintas, também? A negociação das taxas leva em conta os riscos de cada uma das empresas? Em geral, da nossa experiência, a resposta é não. Na melhor das hipóteses haverá alguma variação de taxas entre as empresas, muito mais por percepção da própria empresa do que pelo banco. A empresa em pior situação de crédito tenderá a negociar menos as taxas do que a empresa em melhor situação. É isso que as irá diferenciar. Não é a postura do banco em relação ao risco que a empresa representa que irá definir a taxa de juros da operação, na maioria dos casos.

Este texto procura contribuir para a solução dos problemas citados, apresentando um conjunto de procedimentos e um critério que dilua o instante da decisão, não necessitando mais a definição do sim ou não, pelo menos de forma direta, e permita uma avaliação do risco de crédito que possa ser captada pelas taxas de juros. É o que passamos a examinar.

\section{Um Critério Para a Decisão do Crédito}

Consideremos o exame de um crédito dado por um banco, onde $\mathbf{F}$ é o valor a ser pago no final de um prazo de $\mathbf{d}$ dias, pela empresa que contraiu o empréstimo.

A postura do banco em relação ao crédito é a de examinar o que poderá ocorrer no dia do pagamento. Esta análise é que irá avaliar o risco da operação de crédito, para a empresa em exame, e em seguida definir a taxa de juros da operação.

Para a elaboração do critério teremos de cumprir estas três etapas:

- determinação dos eventos que poderão ocorrer na data de pagamento do empréstimo;

- determinação das probabilidades de ocorrências desses eventos, por empresa;

- determinação da taxa de juros da operação;

- elaboração de um critério de corte do risco a que o banco deve estar sujeito.

Examinemos detalhadamente cada uma destas etapas. 


\section{Determinação dos Eventos que Poderão 0 correr na Data de Pagamento do Empréstimo}

Feito o empréstimo, o banco deve, em princípio, receber a quantia F, préestabelecida pelo contrato, como pagamento do principal, incluindo os juros pelos d dias de uso do capital emprestado.

Naturalmente, o primeiro evento será:

Evento 1: liquidação da operação na data $\mathbf{d}$, recebendo a quantia $\mathbf{F}$, ou seja, a operação é liquidada pontualmente.

Ocorre que muitos problemas poderão acontecer na data de liquidação da operação, tais como: atrasos, pedidos de renovação da operação, cobranças litigiosas, ou mesmo concordatas e falências. Devemos elaborar uma lista desses possíveis eventos e quantificá-los em termos de valores recebidos na data d de liquidação da operação. Para se ter idéia dessa questão consideremos, como exemplo, o caso de uma operação vencida na data $\mathbf{d}$ e que, apesar dos esforços do banco, após 15 dias o pagamento não havia sido efetuado. Admitamos que em uma negociação, após esse prazo, o banco se propôs a cobrar juros e multa pelo atraso. No entanto, no meio das discussões, percebeu-se que era crítica a situação da empresa e a estratégia foi mudada, de forma que o banco resolveu fazer acordo quitando a dívida pelo mesmo valor $\mathbf{F}$ de vencimento na data $\mathbf{d}$, perdendo os juros e multa pelo atraso. Assim, trazendo o valor $\mathbf{F}$, recebido na data $\mathbf{d}+15$ dias, para a data $\mathbf{d}$ podemos considerar que foi recebido na data $\mathbf{d}$, de vencimento da operação, um percentual do valor $\mathbf{F}$, contratado entre as partes.

Do exemplo apresentado, e admitindo-o como fato razoável, poderíamos pensar em um evento que caracterizasse atraso de pagamento e sua correspondente perda, como segue.

Evento 2: $\quad$ liquidação da operação, após negociação, com perdas por atraso de pagamento. $\mathrm{O}$ valor recebido, equivalente na data $\mathbf{d}$, é dado por $\mathrm{r}_{1}$. F onde $0 \leq \mathrm{r}_{1}<1$.

Na mesma linha devemos elaborar os demais eventos e estabelecer o valor recebido, equivalente na data do vencimento da operação, como um percentual do valor $\mathbf{F}$, para cada evento fixado. 
Em nossa opinião e de acordo com nossa experiência estabelecemos como outros eventos relevantes, os seguintes:

Evento 3: $\quad$ liquidação da operação após cobrança judicial. O valor recebido, equivalente da data $\mathbf{d}$, é dado por $\mathrm{r}_{2} . \mathrm{F}$, com $0 \leq \mathrm{r}_{2},<1$.

Evento 4: liquidação da operação após concordata da empresa. O valor recebido, equivalente na data $\mathbf{d}$, é dado por $\mathrm{r}_{3} . \mathrm{F}, \operatorname{com} 0 \leq \mathrm{r}_{3},<1$.

Evento 5: $\quad$ liquidação da operação com falência da empresa. O valor recebido, equivalente da data $\mathbf{d}$, é dado por $\mathrm{r}_{4} . \mathrm{F}, \operatorname{com} 0 \leq \mathrm{r}_{4}<1$. Nesse caso podemos considerar $\mathrm{r}_{4}=0$, o que estará muito próximo da realidade.

Naturalmente, outros eventos poderão ser listados ou alguns dos mencionados serem modificados, o que não altera as idéias básicas dessa proposta.

\section{A Distribuição Padrão de Crédito}

Consideremos a distribuição de probabilidades dada a partir dos eventos listados. Mesmo com modificações nos seus termos ou com acréscimos de outros eventos, voltados para a questão da liquidação do crédito, a distribuição terá a forma do exemplo seguinte:

\begin{tabular}{|l|l|c|c|}
\hline \multicolumn{2}{|c|}{$\begin{array}{c}\text { EVENTOS RELATIVOS AO } \\
\text { PAGAMENTO DO CRÉDITO }\end{array}$} & $\begin{array}{c}\text { VALOR RECEBIDO, } \\
\text { EQUIVALENTE NA DATA } \\
\text { DE VENCIMENTO, } \\
\text { EM REAIS }\end{array}$ & $\begin{array}{c}\text { PROBABILIDADE DE } \\
\text { OCORRENCIA DO } \\
\text { EVENTO } \\
\text { (DECIMAL) }\end{array}$ \\
\hline EVENTO 1 & RECEBIMENTO PONTUAL & F & \\
\hline EVENTO 2 & $\begin{array}{l}\text { RECEBIMENTO COM ATRASO } \\
\text { APÓS NEGOCIAÇO }\end{array}$ & $\mathbf{r}_{\mathbf{1}} \cdot \mathrm{F}$ & \\
\hline EVENTO 3 & $\begin{array}{l}\text { RECEBIMENTO POR VIA } \\
\text { JUDICIAL }\end{array}$ & $\mathbf{r}_{\mathbf{2}} \cdot \mathrm{F}$ & \\
\hline EVENTO 4 & $\begin{array}{l}\text { RECEBIMENTO APÓS } \\
\text { CONCORDATA }\end{array}$ & $\mathbf{r}_{\mathbf{3}} \cdot \mathrm{F}$ & \\
\hline EVENTO 5 & RECEBIMENTO COM FALENCIA & $\mathbf{r}_{4} \cdot$ F & \\
\hline
\end{tabular}

$\operatorname{com} 0 \leq \mathrm{r}_{1}, \mathrm{r}_{2}, \mathrm{r}_{3}, \mathrm{r}_{4},<1$.

Chamaremos as distribuições deste tipo de distribuição padrão de crédito do banco, visto que cada banco terá uma distribuição de probabilidades semelhante a essa, que será usada como padrão para a análise de crédito. Admitindo a aceitação dos cinco eventos apresentados, as diferenças de um banco para outro serão dadas pelos coeficientes $\mathrm{r}_{1}, \mathrm{r}_{2}, \mathrm{r}_{3}, \mathrm{r}_{4}$, fixados de acordo com as políticas de cada banco. 
A escolha dos coeficientes $\mathrm{r}_{1}, \mathrm{r}_{2}, \mathrm{r}_{3}, \mathrm{r}_{4}$ é questão importante; pode ser estabelecida por meio de levantamento estatístico das operações de crédito, quando procuramos obter os resultados destas operações em termos reais, como porcentagens dos valores de liquidação da operação. Levantados esses números, a experiência e julgamento das pessoas também devem ser levados em conta para a fixação destes parâmetros. Chamamos atenção que, para diferentes situações da conjuntura econômica, os parâmetros $\mathrm{r}_{1}, \mathrm{r}_{2}, \mathrm{r}_{3}, \mathrm{r}_{4}$ se devem modificar, implicando este fato um acompanhamento da variação de seus valores. Em princípio é nossa sugestão que, periodicamente, ocorra uma revisão destes parâmetros em função do histórico das operações.

Quando não dispomos de dados históricos ou não queremos utilizá-los, acreditamos que a experiência dos executivos do banco seja suficiente para a fixação dos coeficientes $r_{1}, r_{2}, r_{3}, r_{4}$ de forma que, com o tempo, sejam estabelecidos os ajustes necessários.

Como exemplo consideremos a construção da distribuição padrão de crédito de um banco, estabelecida para cada $\mathrm{R} \$ 1,00$ na data de liquidação, ou seja, $\mathbf{F}=1,00$, com $r_{1}=0,90 ; r_{2}=0,60 ; r_{3}=0,20$ e $r_{4}=0$. A distribuição terá a forma seguinte:

\begin{tabular}{|l|l|c|c|}
\hline \multicolumn{2}{|c|}{$\begin{array}{c}\text { EVENTOS RELATIVOS AO } \\
\text { PAGAMENTO DO CRÉDITO }\end{array}$} & $\begin{array}{c}\text { VALOR RECEBIDO, POR } \\
\text { UNIDADE DE CAPITAL, } \\
\text { EQUIVALENTE A DATA DE } \\
\text { VENCIMENTO, } \\
\text { EM REAIS }\end{array}$ & $\begin{array}{c}\text { PROBABILIDADE } \\
\text { DE CADA EVENTO }\end{array}$ \\
\hline EVENTO 1 & RECEBIMENTO PONTUAL & 1,00 & \\
\hline EVENTO 2 & $\begin{array}{l}\text { RECEBIMENTO COM ATRA } \\
\text { SO, APÓS NEGOCIÇĀO }\end{array}$ & 0,90 & \\
\hline EVENTO 3 & $\begin{array}{l}\text { RECEBIMENTO POR VIA } \\
\text { JUDICIAL }\end{array}$ & 0,60 & \\
\hline EVENTO 4 & $\begin{array}{l}\text { RECEBIMENTO APÓS } \\
\text { CONCORDATA }\end{array}$ & 0,20 & \\
\hline EVENTO 5 & $\begin{array}{l}\text { RECEBIMENTO COM } \\
\text { FALENCIAS }\end{array}$ & 0,00 & \\
\hline
\end{tabular}

Esta distribuição é que será utilizada para todas as avaliações de crédito, de qualquer empresa, que o banco fizer. Vejamos, então, como isto ocorrerá.

\section{Comitê de Crédito-Determinação das Probabilidades de 0 corrência dos Eventos, por Empresa}

Fixada a distribuição padrão de crédito do banco, o comitê de crédito a utilizará para avaliação do crédito de cada empresa. Em nada se modifica o procedimento da área de crédito ou do comitê quanto às discussões em relação à empresa. 
A mudança ocorre no momento da decisão do crédito. Ao invés do sim ou não, cada membro do comitê preencherá o quadro de probabilidades da distribuição padrão de crédito em relação à empresa em estudo.

Em função do conjunto de informações apresentadas sobre a empresa cada membro do comitê deverá elaborar probabilidades, que serão subjetivas, com relação aos eventos listados. Assim deverão dar um número entre zero e a unidade que indique:

- a probabilidade do recebimento ser pontual;

- a probabilidade do recebimento ser com atraso, após negociação;

- a probabilidade do recebimento ocorrer por via judicial;

- a probabilidade de ocorrer a concordata;

- a probabilidade de ocorrer a falência.

Naturalmente, o procedimento é o mesmo, se existirem outros eventos, conforme já comentamos.

Em seguida, são coletados os cartões dos membros do comitê e feitas as médias de probabilidades por evento, o que representará a probabilidade de cada evento em relação à empresa avaliada, com base na data de vencimento do crédito.

Obtemos assim o que chamamos de distribuição padrão de crédito da empresa $\mathbf{X}$, no banco $\mathbf{B}$, que terá a seguinte forma:

\begin{tabular}{|c|c|c|}
\hline & BANCO B & \\
\hline \multicolumn{3}{|c|}{ DISTRIBUIÇÃO: EMPRESA $\mathrm{X}$} \\
\hline EVENTOS & $\begin{array}{c}\text { VALOR RECEBIDO POR } \\
\text { UNIDADE F }\end{array}$ & PROBABILIDADES \\
\hline EVENTO 1 & 1,00 & $\mathbf{p}$ \\
\hline EVENTO 2 & $\mathbf{r}_{1}$ & $\mathbf{q}_{1}$ \\
\hline EVENTO 3 & $\mathbf{r}_{2}$ & $\mathbf{q}_{2}$ \\
\hline EVENTO 4 & $\mathbf{r}_{3}$ & $q_{3}$ \\
\hline EVENTO 5 & $\mathbf{r}_{4}$ & $q_{4}$ \\
\hline
\end{tabular}

A média da distribuição será dada por:

$$
\begin{aligned}
& E[F]=\mu=p+r_{1} q_{1}+r_{2} q_{2}+r_{3} q_{3}+r_{4} q_{4}, \\
& \text { o cálculo de } E\left[F^{2}\right] \text { será dado por: }
\end{aligned}
$$


$E\left[F^{2}\right]=p+r_{1}^{2} \cdot q_{1}+r_{2}^{2} \cdot q_{2}+r_{3}^{2} \cdot q_{3} \cdot r_{4}^{2} \cdot q_{4}$

e o desvio padrão por:

$$
S=S(F)=\sqrt{E\left[F^{2}\right]-\mu^{2}}
$$

Assim, o comitê de crédito nos fornece uma média do valor de resgate $\boldsymbol{\mu}$, por $\mathrm{R} \$$ 1,00 que deveria ser resgatado, e o desvio $\mathbf{S}$ dessa média, que significa o risco da operação.

Se considerarmos o coeficiente de variação, definido por $\mathrm{CV}=\mathbf{S} / \boldsymbol{\mu}$, podemos estabelecer um limite para a aprovação de crédito. Para tanto, devemos fixar um conjunto de probabilidades que definam um padrão crítico de risco, ao qual corresponde $\mathrm{CV}^{*}$, que designaremos por coeficiente de variação crítico. Assim, para empresas que apresentem $\mathrm{CV}>\mathrm{CV}^{*}$ o crédito será rejeitado.

Como exemplo, consideremos a distribuição padrão de crédito de um banco aplicado a uma empresa em condições limites de crédito. Estas condições limites serão definidas pelas possibilidades dos eventos, conforme a tabela.

\begin{tabular}{|c|c|c|}
\hline EVENTOS & VALOR RESGATE F & PROBABILIDADES \\
\hline EVENTO 1 & F=1,00 & 0,900 \\
\hline EVENTO 2 & 0,90 & 0,060 \\
\hline EVENTO 3 & 0,60 & 0,025 \\
\hline EVENTO 4 & 0,20 & 0,010 \\
\hline EVENTO 5 & 0,00 & 0,005 \\
\hline
\end{tabular}

Onde a média é dada por:

$\mathrm{E}[\mathrm{F}]=\boldsymbol{\mu}=1 \times 0,90+0,90 \times 0,06+0,60 \times 0,025+0,20 \times 0,01+0 \times 0,005=0,971$

$\mathrm{e} E\left[\mathrm{~F}^{2}\right]=1^{2} \times 0,90+0,90^{2} \times 0,06+0,60^{2} \times 0,025+0,20^{2} \times 0,01+0^{2} \times 0,005=0,958$

Obtemos o desvio a partir de: 


$$
S=\sqrt{0,958-(0,971)^{2}}=0,123
$$

Assim, o coeficiente de variação crítico será:

$$
\mathrm{CV}^{*}=\frac{0,123}{0,971}=0,1267 \text { ou } 12,67 \%
$$

Nessas condições, para CV $>12,67 \%$ as operações de crédito estarão reprovadas e, caso contrário, aprovadas.

Do exposto, os membros do comitê de crédito não mais decidem na forma de um sim ou não a respeito de um crédito. Pelo contrário, são obrigados a transformarem o conjunto de informações e suas experiências em probabilidades subjetivas, que nos levarão à decisão sobre o crédito.

Naturalmente, muitas críticas existirão em relação ao uso de probabilidades subjetivas e o critério só terá utilidade se o gestor aceitar o seu conceito. Não discutiremos esta questão, mas enfatizamos que o seu uso freqüente tenderá a afinar o conceito e a aplicabilidade das probabilidades subjetivas.

\section{Determinação da Taxa de O peração}

A taxa que o banco deve cobrar do cliente pela operação de empréstimo deve ser formada levando em conta a taxa de captação do banco, que indicaremos por $\mathrm{i}_{\mathrm{c}}, \mathrm{o}$ ganho ou spread do banco, que indicaremos por $\mathrm{i}_{\mathrm{s}}$, e a taxa de risco que o cliente representa, que será anotada por $\mathrm{i}_{\mathrm{R}}$. Vamos supor estas taxas anuais e o prazo da operação em dias, o que comumente ocorre. Na prática, devemos ainda levar em conta o efeito de impostos e outras taxas, que neste estudo deixaremos de lado.

Assim, uma operação de empréstimo feita por um banco a uma empresa, por um período de $\mathbf{d}$ dias, terá uma taxa anual $\mathbf{i}$, dado por:

$$
(1+i)=\left(1+i_{c}\right)\left(1+i_{S}\right)\left(1+i_{R}\right) .
$$

Nosso problema é o de determinar $\mathrm{i}_{\mathrm{R}}$, a taxa de risco da operação, com base na média $\boldsymbol{\mu}$ e no desvio padrão $\mathbf{S}$, calculados a partir da distribuição de probabilidades da empresa, estabelecida pelo comitê de crédito. 
Para o cálculo da taxa de risco $\mathrm{i}_{\mathrm{R}}$ devemos fixar algumas premissas, que nos possibilitarão efetivá-la. Fixaremos essas premissas de forma que obtenhamos o cálculo de $\mathrm{i}_{\mathrm{R}}$ segundo dois enfoques que nos parecem importantes.

Consideremos um empréstimo, feito pelo banco, com valor $\mathbf{F}$ no vencimento, ao final de $\mathbf{d}$ dias. Sabemos, pela distribuição de probabilidades da empresa, que o valor a ser recebido terá como média o valor $\boldsymbol{\mu}$, com desvio $\mathbf{S}$. Da própria construção do modelo, é fácil observar, que $\mathbf{F} \geq \boldsymbol{\mu}$.

Indiquemos por $\boldsymbol{\mu}^{*}$ o valor efetivamente recebido pelo banco na data do vencimento, onde $\mathrm{F} \geq \boldsymbol{\mu}^{*}$; então, a taxa de risco $\mathrm{i}_{\mathrm{R}}$ deve ser tal que corresponda a um acréscimo, ao valor $\mu^{*}$ recebido na data do vencimento, dado por $\mathrm{F}-\boldsymbol{\mu}^{*}$, a fim de recompor $\mathrm{o}$ valor da dívida no vencimento.

Se $\boldsymbol{\mu}^{*}$ é o valor certo a ser recebido na data do vencimento, livre de risco, então ele foi obtido por meio da taxa de captação e do spread do banco, aplicado sobre o principal da operação, que indicaremos por A.

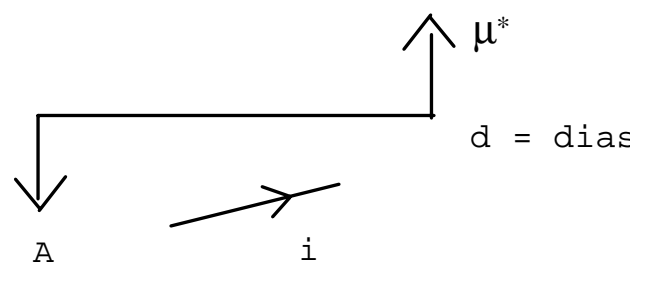

$\operatorname{Logo} \mu^{*}=A\left[\left(1+i_{c}\right)\left(1+i_{s}\right)\right]^{\frac{d}{360}}$; fórmula obtida considerando as taxas anuais.

Como a taxa de risco i $\mathrm{i}_{\mathrm{R}}$ deve recompor o valor $\mathrm{F}$, da data de vencimento, então devemos aplicar o principal A de forma a obter o valor $\mathrm{F}$ por meio de taxas de captação, spread e risco, como segue:

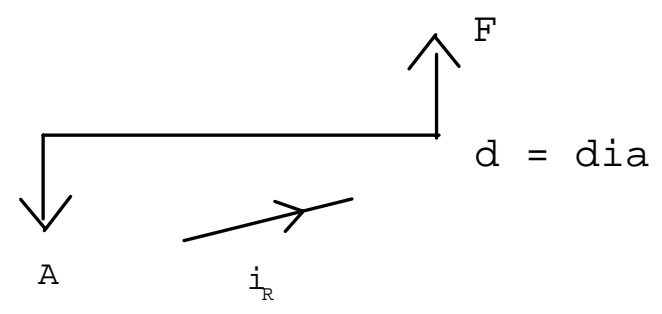




$$
\mathrm{F}=\mathrm{A}\left[\left(1+\mathrm{i}_{\mathrm{c}}\right)\left(1+\mathrm{i}_{\mathrm{s}}\right)\left(1+\mathrm{i}_{\mathrm{R}}\right)\right]^{\frac{\mathrm{d}}{360}}
$$

Substituindo o valor de A, teremos:

$$
\mathrm{F}=\mu^{*} \cdot\left(1+\mathrm{i}_{\mathrm{R}}\right)^{\frac{\mathrm{d}}{360}}
$$

o que nos possibilita obter o valor de $\mathrm{i}_{\mathrm{R}}$, dado por:

$$
i_{R}=\left(\frac{F}{\mu^{*}}\right)^{\frac{360}{d}}-1
$$

Como em geral elaboramos a distribuição de probabilidades com base na unidade de moeda a ser resgatada, ou seja $\mathrm{F}=\mathrm{R} \$ 1,00$, então:

$$
i_{R}=\left(\frac{1}{\mu^{*}}\right)^{\frac{360}{d}}-1,
$$

o que nos dá a taxa de risco em bases anuais.

No caso geral teremos:

$$
i_{R}=\left(\frac{1}{\mu^{*}}\right)^{\frac{1}{n}}-1
$$

onde a taxa será dada na mesma unidade que usarmos para medir o prazo $\mathbf{n}$ da operação.

Evidentemente, o problema não está resolvido pois não conhecemos o valor de $\boldsymbol{\mu}^{*}$, visto que ele representa o valor efetivamente recebido. Nosso problema passa a ser o de estimar o valor de $\boldsymbol{\mu}^{*}$ de forma conveniente para nossos propósitos.

Para tanto, examinemos as possíveis limitações de $\boldsymbol{\mu}^{*}$, como segue: 
- sabemos que $\mathrm{F} \leq \boldsymbol{\mu}$ e $\mathrm{F} \leq \boldsymbol{\mu}^{*}$, representado por:

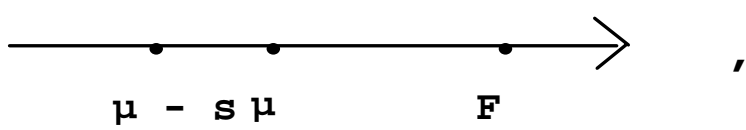

sem que possamos relacionar $\boldsymbol{\mu}^{*}$ com a média $\boldsymbol{\mu}$;

- vamos admitir que seja alta a probabilidade de ocorrer:

$\boldsymbol{\mu}-\mathrm{S} \leq \boldsymbol{\mu}^{*} \leq \boldsymbol{\mu}+\mathrm{S}$

- como $\boldsymbol{\mu}-\mathrm{S} \leq \boldsymbol{\mu} \leq \boldsymbol{\mu}+\mathrm{S}$ então $\left|\boldsymbol{\mu}^{*}-\boldsymbol{\mu}\right|$ será tanto menor quanto menor for o desvio $\mathrm{S}$;

- finalmente, sabemos que quanto menor for o valor de $\mu^{*}$, maior será a taxa de risco iR.

Nessas considerações, propomos, como premissa para o cálculo da ${ }_{\mathrm{R}}$, que:

$$
\boldsymbol{\mu}-\mathrm{S} \leq \boldsymbol{\mu}^{*} \leq \boldsymbol{\mu}
$$

o que estará a favor das condições de risco para o banco e nos possibilita, examinando os extremos, dois enfoques de boa visão prática.

No primeiro enfoque consideramos $\boldsymbol{\mu}^{*}=\boldsymbol{\mu}$ e nessas condições teremos:

$$
i_{R}^{\prime}=\left(\frac{1}{\mu}\right)^{\frac{1}{n}}-1
$$

No caso estamos admitindo que, em grande número de operações de empréstimo, o banco resgatará em média o valor médio da operação. Na prática esse cálculo da taxa de risco ${ }_{\mathrm{R}}$ nos parece interessante para um banco que opere com muitas empresas e baixos valores. Estamos pensando em operações com empresas de porte médio, que envolve capital de giro ou mesmo o crédito direto ao consumidor.

O segundo enfoque é fixado por $\boldsymbol{\mu}^{*}=\boldsymbol{\mu}-\mathrm{S}$ e nessas condições: 


$$
\mathrm{i}_{\mathrm{R}}=\left(\frac{1}{\mu-\mathrm{s}}\right)^{\frac{1}{\mathrm{n}}}-1
$$

Para esse caso estimamos um recebimento menor que a média, o que corresponde a uma taxa de risco i" $R>i$ 'R. Esse tratamento nos parece conveniente para as grandes operações executadas eventualmente, em que a média é menos representativa, e que podemos chamar operações especiais.

Assim, podemos considerar que:

$\mathrm{i}_{\mathrm{R}}$ : representa a taxa de risco das operações freqüentes;

e, $\mathrm{i}$ 'R: representa a taxa de risco das operações especiais.

Nessas condições podemos relacionar as taxas como segue:

$$
\begin{aligned}
& \frac{1+\mathrm{i}_{\mathrm{R}}^{\prime}}{1+i^{\prime{ }_{R}}}=\left(\frac{\mu-\mathrm{s}}{\mu}\right)^{\frac{1}{\mathrm{n}}}, \\
& \text { como } \mathrm{CV} \quad=\frac{\mathrm{s}}{\mu}, \text { então: } \\
& \frac{1+\mathrm{i}_{\mathrm{R}}^{\prime}}{1+\mathrm{i}_{\mathrm{R}}}=(1-\mathrm{CV})^{\frac{1}{\mathrm{n}}}
\end{aligned}
$$

\section{CONCLUSÕES}

Embora a concessão de crédito para empresas tenha recebido pouca atenção nos estudos formais da economia brasileira, acreditamos que um volume expressivo de transações entre empresas, e entre elas e bancos, são feitas a crédito. Uma quase infinita variedade de continuação de transações é realizada numa condição de confiança entre as partes, criando-se acordo entre tomadores e aplicadores de recursos. 
Em todas as concessões de crédito há uma parte de risco. Pode-se admitir um risco regular onde existe pouca dúvida quanto à possibilidade de resgate da dívida. Existe, também, o risco não regular ou marginal, que surge para aqueles clientes não habituais ou com capacidade financeira e habilidade administrativa que deixam dúvidas quanto à possibilidade de liquidez do crédito.

Os estudos tradicionais de concessão de crédito se baseiam quase sempre em análises subjetivas do potencial de pagamento e introduzem alguns instrumentos de garantia que não tornam a concessão de crédito ruim em crédito bom, apenas exigem certos procedimentos adicionais.

No decorrer deste trabalho analisamos os aspectos tradicionais de concessão de créditos pelos bancos, descrevendo os procedimentos habituais de como é tomada a decisão de crédito.

Em seguida, apresentamos uma nova visão, um critério mais quantitativo, para a concessão creditícia, identificando possíveis eventos que possam ocorrer na data do pagamento do empréstimo, bem como procuramos oferecer uma distribuição padrão de crédito, associando aos eventos expectativas probabilísticas. Com base nesses critérios, procuramos identificar as taxas de riscos para as operações e, decorrentes destas, as taxas de remuneração para os empréstimos.

\section{Referências Bibliográficas}

ANDIMA

Associação Nacional das Instituições de Mercado Aberto Súmula 14 - Limites Operacionais, p.2; p.7.

BANCO CENTRAL DO BRASIL.

Resoluções $\mathrm{n}^{\circ}$ s 2099, de 17.09.94 e 2139, de 29.12.94.

BANKS, E.

Volatility and credit risk in the capital markets. Chicago: Probus Publishing Company, 1993.

CARVALHO, S. A.

Desenvolvimento de novas técnicas para a gestão bancária no Brasil. São Paulo, 1993. Tese de Doutorado FEA/ Universidade de São Paulo.

\section{CASSERLEY,D.}

Facing up to the risks. London: John Wiley \& Sons, 1993.

CREDIT POLICY MANUAL Pittsburgh National Bank, PNC International - Banco de Investimentos S.A., p. II C; p. II F. 1987.

DOUAT, J. C.

Desenvolvimento no modelo para administração de carteiras de crédito a pessoas jurídicas em um banco comercial com base na Teoria da Diversificação de Riscos. São Paulo,1994.Tese de Doutorado Fundação Getúlio Vargas. 
KAO, D. L.,

KALLBERG, J. G.

Strategies for measuring and managing risk concentrations in loan portfolios. The Journal of Commercial Lending, p.18-27, 1994.

KOCH, T. W.

Bank management. 2.ed. The Dryden Press, 1992.

LARR, P.,

STAMPLEMAN, A.

Concepts of portfolio mana-gement. Part 2: understanding and using the model. The Journal of Commercial Lending, p. 26-31, 1993.

LULA, G.

Loan portfolio management - Post FDICIA. The Journal of Commercial Lending, p. 15-21, 1993.
SAUNDERS, A.

Financial institutions mana-gement: a modern perspective. Illinois: Richard D. Irwin, 1994.

SECURATO, J. R.

Decisões financeiras em condições de incerteza. São Paulo: Editora Atlas, 1995.

WEILAND, J. M.

Managing portfolios concen-trations through diversification. The Journal of Commercial Lending, p.20-35, 1993.

WYMAN, W. W.

How to improve credit risk management. The Journal of Commercial Lending, p. 2031,1991 . 